\title{
Association between serum thyrotropin within the euthyroid range and obesity
}

\author{
Xiuying Zhang ${ }^{1)}$, Yufeng $\mathrm{Li}^{2}{ }^{2}$, Xianghai Zhou ${ }^{1)}$, Xueyao Han ${ }^{1)}$, Ying $\mathrm{Gao}^{1)}$ and Linong $\mathrm{Ji}^{1)}$ \\ 1) Department of Endocrinology and Metabolism, Peking University People's Hospital, Peking University Diabetes Centre, Beijing \\ 100044, China \\ 2) Department of Endocrinology and Metabolism, Capital Medical University Pinggu Teaching Hospital, Beijing 101200, China
}

\begin{abstract}
The relationship between variations in thyroid function and indices of obesity remains a focus of debate. To explore the associations between thyroid function within the normal range and obesity and to evaluate potential modifying factors, we analyzed a large and well-characterized community cohort in Beijing, China, containing 1,816 men and 1,774 women with serum thyrotropin (TSH) levels within the reference range $(0.55-4.78 \mu \mathrm{IU} / \mathrm{mL})$. Associations between TSH levels and BMI were identified using correlation analysis, ANOVA and Chi-square tests. Logistic regression analyses were used to estimate the impact of serum TSH on obesity before and after adjustment for possible confounding factors. The mean serum TSH was $2.04 \pm 0.94 \mu \mathrm{IU} / \mathrm{mL}$. TSH within the reference range was positively associated with BMI in both genders. Compared with euthyroid adults whose TSH was in the middle quartiles (TSH $1.30-2.60 \mu \mathrm{IU} / \mathrm{mL}$ ) of the reference range, the odds of obesity (BMI $\left.\geq 28.0 \mathrm{~kg} / \mathrm{m}^{2}\right)$ and severe obesity $\left(\mathrm{BMI} \geq 33.0 \mathrm{~kg} / \mathrm{m}^{2}\right)$ was $38 \%(\mathrm{OR}=1.38,95 \% \mathrm{CI} 1.17-1.64)$ and $58 \%(\mathrm{OR}=1.58,95 \% \mathrm{CI} 1.12-2.21)$ more likely, respectively, among those with TSH in the upper quartile. For women, postmenopausal subjects with lower TSH levels had a lower risk of severe obesity (OR $=0.42,95 \%$ CI $0.20-0.91)$ than those in the middle TSH quartile. Positive associations were found between serum TSH within the euthyroid range and obesity, and menopause showed a significant influence on the relationship between TSH level and severe obesity.
\end{abstract}

Key words: Thyroid hormones, Thyrotropin, Obesity, Epidemiology

THE INCIDENCE of obesity is increasing, especially in developing countries. Currently, the prevalence of obesity exceeds $12 \%$ in China [1], suggesting a need to fully understand the risk factors for weight gain. Global differences in the prevalence of obesity are most likely due to genetic susceptibility combined with particular environmental exposures; however, interactions with other factors are far from elucidated. Recent evidence has indicated that serum thyrotropin (TSH) levels are associated with multiple cardiovascular and cerebral vascular outcomes and even mortality, regardless of whether an individual's thyroid function is within the normal range [2-4]. In this context, the association between thyroid function and weight status has seen renewed research interest $[5,6]$.

Submitted Apr. 7, 2018; Accepted Jan. 29, 2019 as EJ18-0140 Released online in J-STAGE as advance publication Mar. 5, 2019 Correspondence to: Linong Ji, Department of Endocrinology and Metabolism, Peking University People's Hospital, Peking University Diabetes Centre, N0.11, Xi Zhi Men Nan Da Jie, Xicheng District, Beijing 100044, China.

E-mail: jiln@bjmu.edu.cn

*These authors contributed equally to this work.
In complex biological systems, thyroid hormones play key roles in all major metabolic pathways, including protein, carbohydrate and lipid metabolism [7]. The contribution of thyroid hormones to maintenance of body weight has been the subject of many studies, and the relationship between overt thyroid dysfunction and body weight has been well-established $[8,9]$. In general, overt hyperthyroidism is typically accompanied by weight loss, whereas the reverse occurs in hypothyroidism. However, the effects of thyroid hormones on fat storage and metabolism have shown paradoxical results in studies involving euthyroid individuals [8]. In addition, the potential mechanisms underlying the relationship between thyroid function and obesity remain to be elucidated.

Although associations between thyroid function within the normal range and obesity have been found in both cross-sectional and longitudinal studies, establishment of a causal relationship is difficult [10]. Moreover, these findings will not necessarily imply an association between thyroid function and obesity because both thyroid function and weight can be affected by a third factor, such as race, gender, age, smoking, nutrition and 
exercise, menopausal status or autoimmune status. Few studies have considered the general population in China and investigated an association between variations in thyroid function and indices of obesity. Based on this background, we sought to describe the status of thyroid function in a large and well-characterized communitybased cohort in China and to explore potential factors modifying the possible associations between thyroid function within the normal range and indices of obesity.

\section{Methods}

\section{Study population}

The data analyzed in this article are from a community-based cohort established for the Pinggu Metabolic Disease Study. This survey was performed in the Pinggu district of Beijing, China from September 2013 to July 2014. Participants were eligible if they were born in Pinggu, were aged 26-76 years, and had lived there for 5 or more years. Based on the national Civil Registration system, a total of 6,583 participants were selected using a multi-stage random sampling process according to gender and age compositions. In the rural area, five towns were first randomly selected from 16 towns; then, 5 villages were randomly selected from each chosen town, and finally, half of the participants were randomly sampled from these 25 chosen villages. The remaining participants were randomly sampled from a randomly chosen urban district (one of two). Finally, 4,002 individuals $(60.8 \%)$ participated in the programme. Therefore, the population sample studied here reflected a typical Chinese community.

In this study, participants were excluded for any of the following reasons: having either hyperthyroidism (TSH $<0.55 \mu \mathrm{IU} / \mathrm{mL}$ ) or hypothyroidism (TSH $>4.78 \mu \mathrm{IU} /$ $\mathrm{mL}$ ); reporting treatment for previous or present thyroid disease (i.e., thyroid hormone, anti-thyroid drugs, thyroid surgery or radioiodine therapy); and taking drugs or other abnormal status that could affect thyroid function. We further excluded participants who lacked TSH or BMI data. After these exclusions, a total of 1,816 men and 1,774 women remained in this analysis.

\section{Questionnaire and physical examination}

All participants in the Pinggu study answered questionnaires regarding demographics, medical history, family history of chronic diseases and other health-related topics. In addition to clinical measurements, the height, weight, waist circumference, blood pressure and heart rate were measured by trained staff according to standardized protocols.

\section{Laboratory measurements}

All participants had fasting blood samples taken to evaluate biochemical profiles, thyroid function and thyroid-related antibodies. The thyroid hormones and thyroid-related antibodies were measured using a supersensitive electrochemiluminescence immunoassay. In our laboratory, the reference range for serum thyroidstimulating hormone (TSH) is $0.55-4.78 \mu \mathrm{IU} / \mathrm{mL}$, with a detection limit of $0.001 \mu \mathrm{IU} / \mathrm{mL}$. The reference intervals were $11.45-23.17 \mathrm{pmol} / \mathrm{L}$ for free thyroxine (FT4), 3.50$6.50 \mathrm{pmol} / \mathrm{L}$ for free triiodothyronine (FT3), $60 \mathrm{IU} / \mathrm{mL}$ for thyroid peroxidase antibodies (TPOAb) and 15 $\mathrm{IU} / \mathrm{mL}$ for thyroglobulin antibody (TGAb). The intraassay coefficient of variation (CV) was less than $8 \%$, and the inter-assay $\mathrm{CV}$ was less than $10 \%$ for all these parameters. Euthyroidism was defined as serum TSH in the range of $0.55-4.78 \mu \mathrm{IU} / \mathrm{mL}$, regardless of the free $\mathrm{T} 4$ concentration. The Pinggu population is considered to have sufficient iodine intake.

\section{Risk factor identification}

Participants were classified as underweight (BMI < $\left.18.5 \mathrm{~kg} / \mathrm{m}^{2}\right)$, normal weight $\left(18.5-23.9 \mathrm{~kg} / \mathrm{m}^{2}\right)$, overweight (24.0-27.9 kg/m ${ }^{2}$ ), or obese; the latter classification was divided into the follow categories: class I obesity (BMI $28.0-29.9 \mathrm{~kg} / \mathrm{m}^{2}$ ), class II obesity (30.0$\left.32.9 \mathrm{~kg} / \mathrm{m}^{2}\right)$ and class III obesity $\left(\geq 33.0 \mathrm{~kg} / \mathrm{m}^{2}\right)$. These classifications were based on criteria issued by the China Diabetes Society [11]. The smoking exposure status was categorized as never smoked, ex-smoker or current smoker. Alcohol consumption was defined as nondrinker, occasional drinker, or drinking 3 or more times per week. Women were considered to be postmenopausal if their menstrual periods had stopped for at least 1 year. The studied postmenopausal individuals here did not undergo estrogen therapy.

\section{Statistical analysis}

Continuous variables were presented as the mean with standard deviation $(\bar{x} \pm \mathrm{SD})$ or the median with interquartile range. Categorical data were presented as number and proportion (\%). The relationships between serum TSH and BMI were evaluated as continuous variables and as categorical variables, respectively. First, the correlations between variables were assessed using linear correlation and/or rank correlation coefficients. Differences in BMI levels among different TSH categories or differences in TSH levels among different obesity degrees were analyzed using analysis of variance (ANOVA) tests. The frequencies were compared using a Chi-square test to deduce the crude relationship between BMI and TSH levels. Finally, multivariate logistic regression analyses were used to determine the impact of TSH levels on 
different BMI ranges according to obesity severity. Adjustments for possible confounders were performed sequentially for gender, age group, smoking status, drinking status, $\mathrm{TPOAb}(+)$, TGAb(+), and menopause for women (models 2-7). Odds ratios (ORs) with 95\% confidence intervals (CIs) were calculated to evaluate the risk of obesity in subjects with lower and higher TSH levels using the middle TSH levels $(1.30-2.60 \mu \mathrm{IU} / \mathrm{mL})$ as the reference group, and a BMI $\geq 33.0 \mathrm{~kg} / \mathrm{m}^{2}$ for severe obesity. The level of significance was set to $5 \%$. All statistical analyses were performed with SPSS version 21 (SPSS Inc, IL, USA).

The study was approved by the ethics committee of Peking University Health Science Center. All participants provided written informed consent.

\section{Results}

\section{Characteristics of the study population}

The overall composition of the survey population is shown in Table S1. A total of 4,002 individuals attended the programme. In this community-based population, $91.39 \%$ of the subjects had normal TSH levels $(0.55 \leqslant$ $\mathrm{TSH} \leqslant 4.78 \mu \mathrm{IU} / \mathrm{mL}), 0.39 \%$ had overt hyperthyroidism $(\mathrm{TSH}<0.55 \mu \mathrm{IU} / \mathrm{mL}$ and FT4 $>23.17 \mathrm{pmol} / \mathrm{L}$ and/or FT3 $>6.50 \mathrm{pmol} / \mathrm{L}), 1.86 \%$ had subclinical hyperthyroidism $(\mathrm{TSH}<0.55 \mu \mathrm{IU} / \mathrm{mL}, 11.45 \mathrm{pmol} / \mathrm{L}<\mathrm{FT} 4<$ 23.17 and $3.50 \mathrm{pmol} / \mathrm{L}<\mathrm{FT} 3<6.50 \mathrm{pmol} / \mathrm{L}), 0.72 \%$ had overt hypothyroidism $(\mathrm{TSH}>4.78 \mu \mathrm{IU} / \mathrm{mL}$ and FT4 < $11.45 \mathrm{pmol} / \mathrm{L}$ ) and $5.63 \%$ had subclinical hypothyroidism $(\mathrm{TSH}>4.78 \mu \mathrm{IU} / \mathrm{mL}$ and $11.45 \mathrm{pmol} / \mathrm{L}<\mathrm{FT} 4<$ $23.17 \mathrm{pmol} / \mathrm{L}$ ). The age specific prevalence of thyroid disorders in this population is shown in Table S2.

A total of 3,590 eligible individuals $(1,816$ men and 1,774 women) with normal-range thyroid function were included in this analysis. As shown in Table 1, the mean age was 49.83 years, with a SD of 11.68 years. The mean BMI was $26.20 \pm 3.73 \mathrm{~kg} / \mathrm{m}^{2}$, with a high prevalence of overweight (41.17\%) and obesity (29.08\%). The proportion of current smokers was $30.08 \%$. The proportion of participants who drank 3 times or more per week was $20.64 \%$. Menopause was reported by $49.17 \%$ of the women. The mean serum TSH was $2.04 \pm 0.94 \mu \mathrm{IU} / \mathrm{mL}$. The proportions of $\mathrm{TPOAb}(+)$ subjects were $8.19 \%$ for men, $14.03 \%$ for women and $11.08 \%$ for men and women combined. The proportions of $\mathrm{TGAb}(+)$ subjects were $4.02 \%$ for men, $16.31 \%$ for women and $10.08 \%$ for the entire study population.

\section{Correlation between TSH and BMI}

Overall, a weak correlation was found between the serum TSH levels and BMI, in both the men $(r=0.07, p$ $=0.004)$ and the women $(r=0.08, p=0.001)$. TSH within the reference range was positively associated with BMI for both genders. No association was found between the serum TPOAb/TGAb levels and BMI, for men and women separately.

The BMI values arranged by different TSH levels by gender are listed in Table 2. The BMIs for the different TSH levels in both genders were different, and a substantial positive association was found between the serum TSH category and BMI (Fig. S1). Compared with subjects in the middle quartile TSH levels $(1.30-2.60 \mu \mathrm{IU} /$ $\mathrm{mL}$ ), the percentage of severe obesity (BMI $\geq 33.0$ $\mathrm{kg} / \mathrm{m}^{2}$ ) was significantly higher in those in the upper quartile TSH level (2.60-4.78 $\mathrm{IU} / \mathrm{mL})$ but was lower in those in the lower quartile TSH level (0.55-1.30 $\mu \mathrm{IU} / \mathrm{mL}$ ) (Table 3 ). The comparisons between TSH category stratum-specific groups showed the same trend of increasing obesity with higher TSH levels (Table S3). This result showed that TSH remained associated with $\mathrm{BMI}$ even when it remained within the normal range.

\section{The impact of TSH on obesity}

Compared with euthyroid adults with TSH in the middle quartiles of the reference range, obesity (BMI $\geq 28.0$ $\left.\mathrm{kg} / \mathrm{m}^{2}\right)$ was $38 \%$ more common $(\mathrm{OR}=1.38,95 \% \mathrm{CI}$ 1.17-1.64) among those with TSH in the upper quartile. This trend was not substantially changed even after adjusting for gender (model 2), age (model 3), smoking status (model 4), drinking status (model 5) and TPOAb/ TGAb (model 6). Among the subjects with a TSH of $2.60-4.78 \mu \mathrm{IU} / \mathrm{mL}$, the prevalence of severe obesity $\left(\mathrm{BMI} \geq 33.0 \mathrm{~kg} / \mathrm{m}^{2}\right)$ was approximately $50 \%$ higher (OR $=1.58,95 \%$ CI $1.12-2.21$ ) than that for the subjects with a TSH of 1.30-2.60 $\mu \mathrm{IU} / \mathrm{mL}$. Inclusion of additional factors in the models (Table 4) did not affect the association between serum TSH and BMI. However, we found a significant influence of menopause status on the association between TSH level and BMI in severe obesity women, with the postmenopausal subjects in the lower TSH quartiles showing a lower risk of severe obesity $(\mathrm{OR}=0.42$, 95\% CI $0.20-0.91$ ) than those in the middle TSH quartiles. To further analyze the impact of the menopause status on the relationship between TSH and obesity, we compared the frequencies of obesity for different TSH levels before and after menopause (Table S4). The results showed that TSH levels were positively associated with BMI after menopause, but not before menopause.

\section{Discussion}

This study was based on a large and wellcharacterized community population in northern China. Here, we observed positive associations between serum 
Table 1 Characteristics of the participants

\begin{tabular}{|c|c|c|c|c|c|c|c|c|}
\hline Category variables & No. & Percent $(\%)$ & Continuous variables & Mean & Median & $25^{\text {th }}$ & $75^{\text {th }}$ & $\mathrm{SD}$ \\
\hline Total number & 3,590 & & Age $(y)$ & 49.83 & 50.04 & 41.22 & 58.48 & 11.68 \\
\hline Male & 1,816 & 50.58 & $\operatorname{BMI}\left(\mathrm{kg} / \mathrm{m}^{2}\right)$ & 26.20 & 25.89 & 23.49 & 28.42 & 3.73 \\
\hline Female & 1,774 & 49.42 & $\mathrm{WC}(\mathrm{cm})$ & 87.05 & 86.85 & 79.00 & 94.50 & 10.65 \\
\hline $\operatorname{BMI}\left(\mathrm{kg} / \mathrm{m}^{2}\right)$ & & & WHR & 0.88 & 0.88 & 0.83 & 0.93 & 0.73 \\
\hline Normal-weight (18.5 ) & 1,068 & 29.75 & $\mathrm{SBP}(\mathrm{mmHg})$ & 130.07 & 128.33 & 117.67 & 140.67 & 17.89 \\
\hline Overweight (24.0 ) & 1,478 & 41.17 & DBP (mmHg) & 78.88 & 78.00 & 71.00 & 85.67 & 11.37 \\
\hline Obesity $(>28.0)$ & 1,044 & 29.08 & $\mathrm{FPG}(\mathrm{mmol} / \mathrm{L})$ & 6.06 & 5.64 & 5.27 & 6.22 & 1.55 \\
\hline Smoking status & & & $2 \mathrm{hPG}(\mathrm{mmol} / \mathrm{L})$ & 7.36 & 6.90 & 5.79 & 8.25 & 2.52 \\
\hline Never & 2,129 & 59.30 & $\mathrm{TG}(\mathrm{mmol} / \mathrm{L})$ & 1.59 & 1.21 & 0.78 & 1.89 & 1.38 \\
\hline Former & 379 & 10.62 & $\mathrm{LDL}(\mathrm{mmol} / \mathrm{L})$ & 2.87 & 2.84 & 2.32 & 3.37 & 0.80 \\
\hline Current & 1,080 & 30.08 & HDL (mmol/L) & 1.16 & 1.11 & 0.95 & 1.30 & 0.31 \\
\hline Drinking status & & & $\mathrm{UA}(\mu \mathrm{mol} / \mathrm{L})$ & 286.87 & 277.00 & 229.00 & 334.00 & 80.70 \\
\hline Nondrinker & 1,869 & 52.06 & $\operatorname{ALT}(\mathrm{U} / \mathrm{L})$ & 23.87 & 20.00 & 15.00 & 27.00 & 14.93 \\
\hline Occasional & 978 & 27.30 & $\mathrm{Cr}(\mu \mathrm{mol} / \mathrm{L})$ & 60.93 & 59.00 & 50.00 & 70.00 & 14.31 \\
\hline$\geqq 3$ times/week & 741 & 20.64 & $\mathrm{TT} 4(\mu \mathrm{g} / \mathrm{dL})$ & 8.55 & 8.60 & 7.50 & 9.60 & 1.60 \\
\hline $\operatorname{ATG}(+)$ & 362 & 10.08 & FT4 (pmol/L) & 16.21 & 16.04 & 14.66 & 17.61 & 2.29 \\
\hline $\operatorname{ATPO}(+)$ & 398 & 11.08 & TT3 (ng/dL) & 117.32 & 116.49 & 104.68 & 128.51 & 18.57 \\
\hline Before-menopause & 903 & 50.93 & FT3 (pmol/L) & 5.00 & 4.98 & 4.65 & 5.35 & 0.53 \\
\hline Post-menopause & 870 & 49.17 & $\mathrm{TSH}(\mu \mathrm{IU} / \mathrm{mL})$ & 2.04 & 1.85 & 1.31 & 2.60 & 0.94 \\
\hline
\end{tabular}

The data are presented as $n$ and \% for category variables; mean \pm standard deviation, median and interquartile range for continuous variables.

Table 2 BMI values arranged by different TSH levels and by gender

\begin{tabular}{|c|c|c|c|c|c|c|}
\hline \multirow{3}{*}{$\mathrm{TSH}(\mu \mathrm{IU} / \mathrm{mL})$} & \multicolumn{3}{|c|}{ Men } & \multicolumn{3}{|c|}{ Women } \\
\hline & \multirow{2}{*}{$N$} & \multicolumn{2}{|c|}{ BMI $\left(\mathrm{kg} / \mathrm{m}^{2}\right)$} & \multirow{2}{*}{$N$} & \multicolumn{2}{|c|}{ BMI $\left(\mathrm{kg} / \mathrm{m}^{2}\right)$} \\
\hline & & Mean & SD & & Mean & $\mathrm{SD}$ \\
\hline $0.55 \sim$ & 541 & 25.83 & 3.61 & 331 & 25.67 & 3.43 \\
\hline $1.30 \sim$ & 940 & 26.28 & 3.56 & 880 & 26.08 & 3.79 \\
\hline \multirow[t]{2}{*}{$2.60 \sim 4.78$} & 335 & 26.84 & 3.92 & 563 & 26.52 & 3.99 \\
\hline & \multicolumn{3}{|c|}{$\mathrm{F}=7.97 p<0.001$} & \multicolumn{3}{|c|}{$\mathrm{F}=5.44 p=0.004$} \\
\hline
\end{tabular}

The data are presented as $n$ and mean \pm standard deviation. $P$ is for the test of two-pairs ANOVA analyses.

TSH and BMI in euthyroid adults, even after adjustment for gender, age and smoking. Using TSH in the middle quartile as the control, the risk of obesity (BMI $\geq 28.0$ $\mathrm{kg} / \mathrm{m}^{2}$ ) was $38 \%$ greater and that of severe obesity (BMI $\geq 33.0 \mathrm{~kg} / \mathrm{m}^{2}$ ) was $58 \%$ greater in those with TSH in the upper quartile.

A number of studies have reported that thyroid dysfunction is associated with body weight and adiposity [6, 8 , 9]. However, the association between normal-range thyroid function and obesity is controversial. A large population-based study in Denmark (the Dan Thyr
Study) showed a positive association between serum TSH and BMI in subjects with normal thyroid function $[12,13]$. Similarly, in the second North-Trøndelag Health Study (HUNT 2) in Norway, a 10.5-year followup of 15,020 people without self-reported thyroid disease found a positive association between changes in TSH and changes in weight and BMI [14]. The Tromsø study, which was another study in Norway, reported that serum TSH within the normal range was positively associated with BMI; this study also found that an increase in serum TSH was associated with an increase in BMI after a 7- 
Table 3 BMI status among different TSH levels ( $\chi^{2}$ test)

\begin{tabular}{|c|c|c|c|c|c|c|c|c|c|c|}
\hline \multirow{3}{*}{$\begin{array}{l}\text { TSH levels } \\
(\mu \mathrm{IU} / \mathrm{mL})\end{array}$} & \multicolumn{5}{|c|}{ Men } & \multicolumn{5}{|c|}{ Women } \\
\hline & \multicolumn{5}{|c|}{ BMI groups $(N, \%)$} & \multicolumn{5}{|c|}{ BMI groups $(N, \%)$} \\
\hline & $18.5 \sim$ & $24 \sim$ & $28 \sim$ & $30 \sim$ & $\geq 33$ & $18.5 \sim$ & $24 \sim$ & $28 \sim$ & $30 \sim$ & $\geq 33$ \\
\hline $0.55 \sim$ & 179 (33.09) & $220(40.67)$ & $72(13.31)$ & $53(9.80)$ & $17(3.14)$ & $113(34.14)$ & $144(43.50)$ & $37(11.18)$ & $29(8.76)$ & $8(2.42)$ \\
\hline $1.30 \sim$ & $255(27.07)$ & $415(44.27)$ & $140(14.86)$ & $95(10.08)$ & $35(3.72)$ & $281(31.97)$ & $357(40.50)$ & $104(11.83)$ & $91(10.35)$ & $47(5.35)$ \\
\hline $2.60 \sim 4.78$ & $84(25.07)$ & $127(37.91)$ & $61(18.21)$ & $39(11.64)$ & $24(7.16)$ & $157(27.89)$ & $214(38.01)$ & $102(18.12)$ & $52(9.24)$ & $38(6.75)$ \\
\hline
\end{tabular}

The data are presented as $n$ and \%.P is for the trend across quartiles.

Table 4 Effects of the influencing factors on BMI for the participants with normal TSH using logistic regression analysis

\begin{tabular}{|c|c|c|c|c|c|c|c|c|c|c|c|c|c|}
\hline \multirow{3}{*}{ Model } & \multirow{3}{*}{ factors } & \multicolumn{6}{|c|}{$\mathrm{BMI} \geq 28\left(\mathrm{~kg} / \mathrm{m}^{2}\right)$} & \multicolumn{6}{|c|}{$\mathrm{BMI} \geq 33\left(\mathrm{~kg} / \mathrm{m}^{2}\right)$} \\
\hline & & \multicolumn{3}{|c|}{ L-TSH } & \multicolumn{3}{|c|}{ H-TSH } & \multicolumn{3}{|c|}{ L-TSH } & \multicolumn{3}{|c|}{ H-TSH } \\
\hline & & OR & $95 \% \mathrm{CI}$ & $p$ & OR & $95 \% \mathrm{CI}$ & $p$ & OR & $95 \% \mathrm{CI}$ & $p$ & OR & $95 \% \mathrm{CI}$ & $p$ \\
\hline 1 & TSH & 0.85 & $0.70-1.02$ & 0.078 & 1.38 & $1.17-1.64$ & $<0.001$ & 0.63 & $0.40-0.99$ & 0.044 & 1.58 & $1.12-2.21$ & 0.009 \\
\hline 2 & $+\operatorname{Sex}$ & 0.83 & $0.69-1.00$ & 0.055 & 1.41 & $1.18-1.67$ & $<0.001$ & 0.64 & $0.40-1.00$ & 0.051 & 1.55 & $1.10-2.18$ & 0.013 \\
\hline 3 & +age & 0.84 & $0.69-1.07$ & 0.059 & 1.43 & $1.21-1.70$ & $<0.001$ & 0.64 & $0.41-1.02$ & 0.058 & 1.62 & $1.15-2.30$ & 0.006 \\
\hline 4 & + smoking & 0.84 & $0.70-1.01$ & 0.070 & 1.42 & $1.19-1.69$ & $<0.001$ & 0.65 & $0.41-1.03$ & 0.063 & 1.62 & $1.15-2.29$ & 0.006 \\
\hline 5 & +drinking & 0.85 & $0.70-1.02$ & 0.078 & 1.43 & $1.20-1.70$ & $<0.001$ & 0.65 & $0.41-1.02$ & 0.062 & 1.64 & $1.16-2.33$ & 0.005 \\
\hline 6 & + Antibody & 0.85 & $0.70-1.02$ & 0.081 & 1.42 & $1.19-1.69$ & $<0.001$ & 0.65 & $0.41-1.03$ & 0.064 & 1.65 & $1.16-2.34$ & 0.005 \\
\hline 7 & + menopause & 0.71 & $0.53-0.97$ & 0.029 & 1.31 & $1.03-1.64$ & 0.026 & 0.42 & $0.20-0.91$ & 0.028 & 1.28 & $0.82-1.99$ & 0.288 \\
\hline
\end{tabular}

The data are presented as odds ratios (OR) with $95 \%$ CIs.

$P$ is for the trend of regression analysis.

year follow-up in nonsmoking men and women [15]. In the Framingham Study, the cross-sectional survey reported that the baseline mean weight increased progressively from the lowest to the highest TSH quartile, and the longitudinal evaluation showed that a rise in TSH during 3.5-year follow-up was associated with weight gain in both women and men [16]. Prior to this study, the differences in previous studies were thought to have possibly derived from differences in ethnicity. The majority of studies from Western countries appeared to have shown positive findings, whereas studies from Asian populations did not show significant associations between TSH levels and obesity $[17,18]$. However, associations were recently observed between a serum TSH concentration within the normal range and body weight and BMI in Japanese men and Korean women [19, 20]. In contrast, two studies from Australia and the UK reported a lack of association between TSH and BMI in euthyroid subjects [21, 22]. In addition to the potential influence of ethnicity, the study population, design, sample size, detection methods and cut off settings may also affect the consistency of research results. Especially in Asian countries, more and large longitudinal cohort studies are needed to explore this issue.
The influence of smoking on the association between serum TSH and obesity was evaluated in several studies, although the results were not uniform. In the present study, we found that the smoking status had no effect on the association between TSH level and obesity indices. In line with our results, the HUNT Study in Norway and the Busselton Thyroid Study in Australia found no statistically significant differences in terms of gender or smoking status [14, 21]. In contrast, three studies reported a positive association between BMI and serum TSH among nonsmokers only, and one study found the association to be stronger among current smokers than among nonsmokers [19, 21, 23]. Tobacco smoking has complex effects on thyroid function and body weight, and the mechanisms of these effects needs to be further explored.

In addition, few studies have addressed the potential effect of menopause on the association between TSH and obesity. In a large Brazilian population, a weaker association between BMI and TSH was found among postmenopausal women than among premenopausal women [24]. In the multivariate logistic regression analyses in the present study, the inclusion of factors such as gender, age, smoking and menopause status in the model did not significantly change the association between serum TSH 
and obesity. However, when we took a BMI $\geq 33 \mathrm{~kg} / \mathrm{m}^{2}$ as a definition of the dependent variable, we found that menopause status had a significant influence on the relationship between TSH and severe obesity in women. Postmenopausal subjects with lower TSH levels had a smaller risk $(\mathrm{OR}=0.42)$ of severe obesity. One possible explanation is that relatively high thyroid hormone levels help to increase energy consumption and prevent weight gain.

Thyroid autoimmunity, as indicated by positive TPOAb and TGAb, was considered to play an important role in the development of hypothyroidism, which might be followed by weight gain. The proportions of euthyroid subjects with TPOAb $(+)$ and TGAb $(+)$ were $11.08 \%$ and $10.08 \%$, respectively, in this natural population. No association was found between the serum $\mathrm{TPOAb} / \mathrm{TGAb}$ level and BMI in the subjects with normal thyroid function. This lack of association remained when the analysis was repeated separately in men and women.

Mechanistically, thyroid hormones physiologically mediate energy expenditure and thermogenesis [7, 25]. TSH and thyroid hormones receptors are widely expressed in adipose tissue and mediate both lipogenesis and lipolysis $[10,26]$. Some studies have suggested that increased TSH can directly stimulate adipogenesis and fat accumulation or that a certain degree of TSH resistance exists [27, 28]. However, thyroid hormones and obesity should not be considered to have a one-way association, because adipose tissue may influence TSH and thyroid hormones synthesis $[29,30]$. In recent years, the adipocyte-derived hormone, leptin, has gained more attention regarding its regulation of the thyroid axis by stimulating TSH biosynthesis or by decreasing thyroid hormone resistance [31-33]. Notably, in the euthyroid range of the thyroid status, we must be cautious when making judgments related to whether changes in TSH precede changes in weight or vice versa.

The strengths of this study include the relatively large sample size taken from a natural population and the detailed demographic, physical examination, medical history and laboratory indicators information. The subjects included in this analysis were considered to be healthy euthyroid individuals because individuals with self-reported thyroid disorders, basic diseases or abnor- mal thyroid function were excluded. Well-characterized covariate data enabled us to perform multivariableadjusted analyses. Moreover, we performed six regression models to determine the impact of TSH levels on obesity before and after adjustments for potential confounders. These advantages allow relatively reliable evaluations of the associations of interest and generalizability of the findings. However, the cross-sectional design of the study limited our ability to infer causal relationships between variations in TSH and obesity. We also lacked data regarding the serum leptin concentrations to evaluate their role in the body fat-TSH association. More longitudinal and/or experimental studies are warranted to answer questions regarding whether the variation in thyroid function can be used as a risk factor to guide identification and prevention in individuals at risk for weight gain.

In conclusion, we show here that serum TSH within the euthyroid range and obesity had a positive association in a large community-based population in China. The risk of severe obesity was significantly higher with the increase in the level of TSH, especially for those in the upper normal TSH range. A significant influence of menopause was found on the relationship between TSH levels and severe obesity.

\section{Acknowledgements}

This work was supported through a grant from Beijing Science and Technology Committee (D131100005313008). This project was also supported by NIH research training grant R25 TW009345 funded by the Fogarty International Center. We thank all the participants for agreeing to join this study. We are grateful to the research teams from the endocrinology and metabolic department of Beijing Pinggu Hospital and Peking University People's hospital for their contribution to field survey and data collection.

\section{Disclosure Statement}

The authors confirm that the manuscript has not been published or is under consideration for publication elsewhere. The authors declare that they have no conflicts of interest.

\section{Reference}

1. Tian Y, Jiang C, Wang M, Cai R, Zhang Y, et al. (2016) BMI, leisure-time physical activity, and physical fitness in adults in China: results from a series of national surveys, 2000-14. Lancet Diabetes Endocrinol 4: 487-497.
2. Chaker L, Baumgartner C, den Elzen WP, Collet TH, Ikram MA, et al. (2016) Thyroid function within the reference range and the risk of stroke: an individual participant data analysis. J Clin Endocrinol Metab 101: 4270-4282. 
3. Inoue K, Tsujimoto T, Saito J, Sugiyama T (2016) Association between serum thyrotropin levels and mortality among euthyroid adults in the United States. Thyroid 26: 1457-1465.

4. Cappola AR, Arnold AM, Wulczyn K, Carlson M, Robbins J, et al. (2015) Thyroid function in the euthyroid range and adverse outcomes in older adults. J Clin Endocrinol Metab 100: 1088-1096.

5. Pearce EN (2012) Thyroid hormone and obesity. Curr Opin Endocrinol Diabetes Obes 19: 408-413.

6. Laurberg P, Knudsen N, Andersen S, Carle A, Pedersen IB, et al. (2012) Thyroid function and obesity. Eur Thyroid J 1: 159-167.

7. Brent GA (2012) Mechanisms of thyroid hormone action. $J$ Clin Invest 122: 3035-3043.

8. de Moura Souza A, Sichieri R (2011) Association between serum TSH concentration within the normal range and adiposity. Eur J Endocrinol 165: 11-15.

9. McAninch EA, Bianco AC (2014) Thyroid hormone signaling in energy homeostasis and energy metabolism. Ann N Y Acad Sci 1311: 77-87.

10. Santini F, Marzullo P, Rotondi M, Ceccarini G, Pagano L, et al. (2014) Mechanisms in endocrinology: the crosstalk between thyroid gland and adipose tissue: signal integration in health and disease. Eur J Endocrinol 171: R137R152.

11. Zhou BF (2002) Predictive values of body mass index and waist circumference for risk factors of certain related diseases in Chinese adults - study on optimal cut-off points of body mass index and waist circumference in Chinese adults. Biomed Environ Sci 15: 83-96.

12. Knudsen N, Laurberg P, Rasmussen LB, Bulow I, Perrild $\mathrm{H}$, et al. (2005) Small differences in thyroid function may be important for body mass index and the occurrence of obesity in the population. $J$ Clin Endocrinol Metab 90: 4019-4024.

13. Bjergved L, Jorgensen T, Perrild H, Laurberg P, Krejbjerg A, et al. (2014) Thyroid function and body weight: a community-based longitudinal study. PLoS One 9: e93515.

14. Svare A, Nilsen TI, Bjoro T, Asvold BO, Langhammer A (2011) Serum TSH related to measures of body mass: longitudinal data from the HUNT Study, Norway. Clin Endocrinol (Oxf) 74: 769-775.

15. Nyrnes A, Jorde R, Sundsfjord J (2006) Serum TSH is positively associated with BMI. Int $J$ Obes (Lond) 30: 100-105.

16. Fox CS, Pencina MJ, D'Agostino RB, Murabito JM, Seely $\mathrm{EW}$, et al. (2008) Relations of thyroid function to body weight: cross-sectional and longitudinal observations in a community-based sample. Arch Intern Med 168: 587-592.

17. Shon HS, Jung ED, Kim SH, Lee JH (2008) Free T4 is negatively correlated with body mass index in euthyroid women. Korean J Intern Med 23: 53-57.

18. Takashima N, Niwa Y, Mannami T, Tomoike H, Iwai N (2007) Characterization of subclinical thyroid dysfunction from cardiovascular and metabolic viewpoints: the Suita study. Circ J 71: 191-195.

19. Sakurai M, Nakamura K, Miura K, Yoshita K, Takamura $\mathrm{T}$, et al. (2014) Association between a serum thyroidstimulating hormone concentration within the normal range and indices of obesity in Japanese men and women. Intern Med 53: 669-674.

20. Oh JY, Sung YA, Lee HJ (2013) Elevated thyroid stimulating hormone levels are associated with metabolic syndrome in euthyroid young women. Korean J Intern Med 28: $180-186$.

21. Makepeace AE, Bremner AP, O'Leary P, Leedman PJ, Feddema P, et al. (2008) Significant inverse relationship between serum free $\mathrm{T} 4$ concentration and body mass index in euthyroid subjects: differences between smokers and nonsmokers. Clin Endocrinol (Oxf) 69: 648-652.

22. Manji N, Boelaert K, Sheppard MC, Holder RL, Gough $\mathrm{SC}$, et al. (2006) Lack of association between serum TSH or free T4 and body mass index in euthyroid subjects. Clin Endocrinol (Oxf) 64: 125-128.

23. Asvold BO, Bjoro T, Vatten LJ (2009) Association of serum TSH with high body mass differs between smokers and never-smokers. J Clin Endocrinol Metab 94: 50235027.

24. Souza Ade M, Sichieri R (2011) Relationship between body mass index and thyrotropin in euthyroid women: differences by smoking, race and menopausal status. Obes Facts 4: 175-179.

25. Sorisky A, Bell A, Gagnon A (2000) TSH receptor in adipose cells. Horm Metab Res 32: 468-474.

26. Silva JE (2003) The thermogenic effect of thyroid hormone and its clinical implications. Ann Intern Med 139: 205-213.

27. Reinehr T (2010) Obesity and thyroid function. Mol Cell Endocrinol 316: 165-171.

28. Winter WE, Signorino MR (2001) Review: molecular thyroidology. Ann Clin Lab Sci 31: 221-244.

29. Rotondi M, Leporati P, La Manna A, Pirali B, Mondello $\mathrm{T}$, et al. (2009) Raised serum TSH levels in patients with morbid obesity: is it enough to diagnose subclinical hypothyroidism? Eur J Endocrinol 160: 403-408.

30. Feldt-Rasmussen U (2007) Thyroid and leptin. Thyroid 17: 413-419.

31. Menendez C, Baldelli R, Camina JP, Escudero B, Peino R, et al. (2003) TSH stimulates leptin secretion by a direct effect on adipocytes. J Endocrinol 176: 7-12.

32. Mantzoros CS, Magkos F, Brinkoetter M, Sienkiewicz E, Dardeno TA, et al. (2011) Leptin in human physiology and pathophysiology. Am J Physiol Endocrinol Metab 301: E567-E584.

33. Dietlein M, Kahaly G, Kobe C, Schmidt M, Derwahl KM, et al. (2008) Obesity, energy regulation and thyroid function: is borderline elevated TSH-level the cause or secondary phenomenon of obesity. Nuklearmedizin 47: 181-187 (In German). 